\title{
PENERAPAN METODE EKSPONENSIAL PADA SIMULASI ANTREAN
}

\author{
Yuliani $^{1 *}$ \\ Iluh Sriwati ${ }^{2}$ \\ Muhammad Ilyas ${ }^{3}$ \\ ${ }^{1,2}$ Program Studi Matematika Universitas Cokroaminoto Palopo, Indonesia \\ ${ }^{3}$ Prodi Pendidikan Matematika Universitas Cokroaminoto Palopo, Palopo, Indonesia \\ yulimath2507@gmail.com ${ }^{*}$ \\ iluhsriwati08@gmail.com ${ }^{2}$ \\ muhammadilyas@uncp.ac.id ${ }^{3}$
}

\begin{abstract}
Abstrak
Penelitian ini bertujuan untuk mengetahui penerapan metode eksponensial pada simulasi antrean yang ada di bank X. Data yang digunakan dalam penelitian ini diperoleh secara langsung dari PT Bank X dan dianalisis menggunakan bantuan software QM for Windows. Dari simulasi yang dilakukan diperoleh hasil bahwa untuk mengoptimalkan dan mempertahankan pelayanan yang ada di Bank X dilakukan penambahan teller pada jam kerja pukul 09:00-10:00. Dengan demikian terjadi pengurangan waktu ratarata yang dihabiskan seorang nasabah untuk menunggu dalam antrean yaitu dari sebanyak 4,51 menit setelah dilakukan penambahan teller menjadi 0,1 menit. Selain itu terjadi pula pengurangan nasabah yang mengantre dari 2 orang menjadi 0 orang.
\end{abstract}

Kata Kunci: Metode eksponensial, Teori antrean, Multi Channel-Single Phase.

Diterbitkan Oleh:

Fakultas Sains

Program Studi Matematika

Universitas Cokroaminoto Palopo

Copyright (C) 2021 The Author (s)

This article is licensed under CC BY 4.0 License

(cc) $\mathrm{BY}$ 


\section{PENERAPAN METODE EKSPONENSIAL PADA SIMULASI} ANTREAN

\section{Pendahuluan}

Antrean terjadi jika orang, komponen mesin atau unit barang sedang menunggu untuk menerima layanan dari fasilitas layanan yang beroperasi pada kapasitas tertentu, sehingga terjadi antrean, membuat mereka untuk sementara waktu tidak dapat memberikan/memperoleh layanan. Pada saat nasabah menunggu untuk mendapatkan jasa layanan, diperlukan sistem antrean yang baik sehingga proses pelayanan dapat berjalan sesuai dengan standar pelayanan. Sistem antrean PT. Bank X telah mengalami beberapa kali perubahan. Mulanya model antrean menggunakan sistem manual yang sangat sederhana, pelanggan mengantre di jalur pelayanan kemudian memilih teller kosong. Kemudian memperbarui model antrean, yaitu pelanggan dibagi menjadi dua baris yang berbeda untuk antrean atau disebut T-model antrean (Ardi, 2015). Berikutnya adalah model antrean, dimana setiap teller memiliki antreannya masing-masing, sehingga pelanggan dapat dengan leluasa memilih teller yang kosong. Karena adanya peningkatan permintaan, maka model antrean menggunakan model antrean otomatis, dimana pelanggan memilih nomor antrean dan menunggu nomor tersebut dipanggil (Mehandiratta, 2011).

Peluang distribusi waktu layanan biasanya mengikuti distribusi probabilitas eksponensial, yang memberikan informasi berguna tentang operasi yang terjadi pada sistem antrean. Sifat distribusi eksponensial yang membuat distribusi ini mudah dianalisis adalah tidak ada hubungannya dengan waktu (memory less proferty atau sifat pelupa) (Andika, A.M.H dan Novriyenni, 2018). Melalui penelitian ini penulis ingin melakukan simulasi antrean menggunakan metode eksponensial.

\section{Metode Penelitian}

Jenis penelitian ini adalah deskriptif yang menjelaskan bagaimana simulasi pelayanan nasabah pada PT Bank X dengan menggunakan metode eksponensial. Sumber data yang digunakan dalam penelitian ini berupa data kedatangan nasabah setiap hari kerja serta waktu yang dibutuhkan nasabah berada dalam sistem pelayanan pada PT Bank X yang diperoleh secara langsung melalui observasi pada PT Bank X. Simulasi dalam penelitian ini menggunakan bantuan software QM for Windows. 


\section{Hasil dan Pembahasan}

Berikut data kedatangan nasabah setiap hari kerja pada PT Bank X selama satu minggu hari kerja (Lihat Tabel 1).

Tabel 1. Data Kedatangan Nasabah Per Hari

\begin{tabular}{|c|c|c|c|c|c|c|c|}
\hline \multirow[b]{2}{*}{ No } & \multirow[b]{2}{*}{ Jam Kerja } & \multicolumn{4}{|c|}{ Hari/Tanggal Kerja } & \multirow[b]{2}{*}{$\begin{array}{c}\text { Selasa/ } \\
08-12-20\end{array}$} & \multirow[b]{2}{*}{ Total } \\
\hline & & $\begin{array}{c}\text { Rabu/ } \\
02-12-20\end{array}$ & $\begin{array}{c}\text { Kamis / } \\
03-12-20\end{array}$ & $\begin{array}{c}\text { Jum'at / } \\
04-12-20\end{array}$ & $\begin{array}{c}\text { Senin / } \\
07-12-20\end{array}$ & & \\
\hline 1 & 08:00 - 09:00 & 39 & 27 & 21 & 25 & 23 & 135 \\
\hline 2 & 09:00 - 10:00 & 66 & 30 & 16 & 23 & 20 & 155 \\
\hline 3 & $10: 00-11: 00$ & 35 & 23 & 12 & 15 & 18 & 103 \\
\hline 4 & $11: 00-12: 00$ & 12 & 19 & 10 & 10 & 15 & 66 \\
\hline 5 & $12: 00-13: 00$ & 10 & 14 & 15 & 12 & 14 & 65 \\
\hline 6 & $13: 00-14: 00$ & 10 & 17 & 10 & 15 & 8 & 60 \\
\hline 7 & $14: 00-15: 00$ & 12 & 12 & 5 & 11 & 9 & 49 \\
\hline 8 & $15: 00-16: 00$ & 8 & 10 & 0 & 8 & 5 & 31 \\
\hline \multicolumn{2}{|c|}{$\begin{array}{c}\text { Jumlah Nasabah } \\
\text { Per Hari }\end{array}$} & 192 & 152 & 89 & 119 & 112 & 664 \\
\hline
\end{tabular}

Sumber: Data primer (2020)

Adapun rata-rata tingkat kedatangan nasabah dan rata-rata tingkat pelayanan teller dapat dilihat pada Tabel 2 berikut.

Tabel 2. Data Rata-rata Tingkat Kedatangan Nasabah

\begin{tabular}{cccc}
\hline No & Jam Kerja & Jumlah Nasabah & Lambda $(\lambda)$ \\
\hline 1 & $08: 00-09: 00$ & 135 & 27 \\
2 & $09: 00-10: 00$ & 155 & 31 \\
3 & $10: 00-11: 00$ & 103 & 20,6 \\
4 & $11: 00-12: 00$ & 66 & 13,2 \\
5 & $12: 00-13: 00$ & 65 & 13 \\
6 & $13: 00-14: 00$ & 60 & 12 \\
7 & $14: 00-15: 00$ & 49 & 9,8 \\
8 & $15: 00-16: 00$ & 31 & 6,2 \\
\hline
\end{tabular}

Sumber: Data primer setelah diolah (2020)

Pada PT Bank X Jumlah kedatangan rata-rata persatuan waktu $(\lambda)$ dalam Tabel 3 dapat dihitung menggunakan persamaan (1). PT Bank X dalam proses transaksi memiliki standar waktu pelayanan untuk masing-masing telleryaitu sebanyak 3 menit dalam upaya mempertahankan tingkat produktivitas (Darwis, 2014). Maka jumlah rata-rata tingkat pelayanan $(\mu)$ menggunakan persamaan (2) adalah 20 orang yang diperoleh dari:

$$
\mu=\frac{1 \text { orang }}{3 \text { menit }} \times 60 \text { menit }=20
$$

Pada model sistem antrean yang digunakan PT Bank X adalah Multi Channel-Single Phase atau jalur berganda, maka peneliti dapat menganalisis menggunakan model B: Multiple 
Channel Query System (M/M/S) seperti pada Lampiran 2 dan Lampiran 3 yang dirangkum pada Tabel 3 berikut.

Tabel 3. Hasil Analisis Sistem Antrean

\begin{tabular}{clllllllll}
\hline \multirow{2}{*}{ Jam Kerja } & \multicolumn{10}{c}{ Analisis Sistem Antrean } \\
\cline { 2 - 10 } & $M$ & $\lambda$ & $\mu$ & $\rho$ & $P_{0}$ & $L_{s}$ & $W_{s}$ & $L_{q}$ & $W_{q}$ \\
\hline $08: 00-09: 00$ & 2 & 27 & 20 & 0,68 & 0,19 & 2,48 & 5,51 & 1,13 & 2,51 \\
09:00-10:00 & 2 & 31 & 20 & 0,78 & 0,13 & 3,88 & 7,51 & 2,33 & 4,51 \\
$10: 00-11: 00$ & 2 & 20,6 & 20 & 0,52 & 0,32 & 1,4 & 4,08 & 0,37 & 1,08 \\
$11: 00-12: 00$ & 2 & 13,2 & 20 & 0,33 & 0,5 & 0,74 & 3,37 & 0,08 & 0,37 \\
$12: 00-13: 00$ & 2 & 13 & 20 & 0,33 & 0,51 & 0,73 & 3,35 & 0,08 & 0,35 \\
$13: 00-14: 00$ & 2 & 12 & 20 & 0,3 & 0,54 & 0,66 & 3,3 & 0,06 & 0,3 \\
14:00-15:00 & 2 & 9,8 & 20 & 0,25 & 0,61 & 0,52 & 3,19 & 0,03 & 0,19 \\
15:00-16:00 & 2 & 6,2 & 20 & 0,16 & 0,73 & 0,32 & 3,07 & 0,01 & 0,07 \\
\hline
\end{tabular}

Sumber: Data primer setelah diolah (2020)

Berdasarkan Tabel 4, dengan jumlah jalur yang terbuka $(M)$ adalah 2 teller dapat dijelaskan bahwa:

a. Probabilitas terdapat 0 orang dalam sistem $\left(P_{0}\right)=\operatorname{Prob}($ num in $\mathrm{sys}=k$ )

Probabilitas terdapat 0 orang dalam sistem terendah terjadi pada jam kerja 09:00 - 10:00 yaitu sebesar 0,13 atau 13\%. Pada jam kerja tersebut pelayanan teller dalam keadaan sepi sangat kecil, semakin besar persentasenya maka memungkinkan semakin besar pelayanan teller dalam keadaan sepi.

b. Tingkat utilitas atau kesibukan teller $(\rho)=$ Average serverutilization

Rata-rata tingkat utilitas atau kesibukan teller paling tinggi terjadi pada jam kerja 09:00 - 10:00 sebesar 0,78 atau 78\%. Hal ini berarti bahwa tingkat utilitas atau kesibukan teller yang melayani nasabah dalam kondisi ramai, nasabah akan merasa lebih nyaman apabila datang pada siang hari setelah jam istirahat untuk meminimalisir lamanya mengantre di teller. Semakin tinggi persentase nilai $\rho$ maka tingkat kesibukan teller semakin besar.

c. Rata-rata jumlah nasabah dalam sistem $\left(L_{s}\right)=$ Average number in the system

Rata-rata jumlah nasabah dalam sistem terpanjang terjadi pada jam kerja 09:00-10:00 yaitu sebanyak 3,88 atau 4 orang. Pada kondisi ini nasabah diharuskan mengantre menunggu nomor antrean dipanggil untuk memperoleh pelayanan teller.

d. Rata-rata jumlah nasabah dalam antrean $\left(L_{q}\right)=$ Average number in the queue

Rata-rata jumlah nasabah dalam antrean terpanjang terjadi pada jam kerja 09:00 - 10:00 yaitu sebanyak 2,33 atau 2 orang. Pada jam kerja tersebut diakibatkan oleh banyaknya nasabah yang mengantre, rata-rata jumlah nasabah dalam antrean menggambarkan panjangnya antrean seorang nasabah untuk memperoleh pelayanan dalam sistem antrean. 
e. Waktu rata-rata yang dihabiskan seorang nasabah dalam sistem $\left(W_{s}\right)=$ Average time in the system

Waktu rata-rata yang dihabiskan seorang nasabah dalam sistem terpanjang terjadi pada jam kerja 09:00-10:00 yaitu sebanyak 7,51 menit. Pada jam kerja tersebut sistem antrean dalam keadaan sibuk karena adanya nasabah yang menunggu untuk memperoleh pelayanan dalam sistem.

f. Waktu rata-rata yang dihabiskan seorang nasabah untuk menunggu dalam antrean terpanjang terjadi pada jam kerja 09:00-10:00 yaitu sebanyak 4,51 menit.

Simulasi

Berikut diberikan Hasil Waiting Lines pada jam sibuk (09.00-10.00).

\begin{tabular}{|c|c|c|c|c|c|}
\hline \multicolumn{6}{|c|}{ Jam Kerja 09:00 - 10:00 Solution } \\
\hline Parameter & Value & Parameter & Value & Minutes & Seconds \\
\hline $\mathrm{M} / \mathrm{M} / \mathrm{s}$ & & Average server utilization & ,78 & & \\
\hline Arrival rate(lambda) & 31 & Average number in the queue $(\mathrm{Lq})$ & 2,33 & & \\
\hline Service rate(mu) & 20 & Average number in the system $(L)$ & 3,88 & & \\
\hline \multirow[t]{2}{*}{ Number of servers } & 2 & Average time in the queue $(\mathrm{Wq})$ & ,08 & 4,51 & 270,7 \\
\hline & & Average time in the system(W) & ,13 & 7,51 & 450,7 \\
\hline
\end{tabular}

Tabel 4. hasil simulasi probabilitas pada jam sibuk (09.00-10.00)

\begin{tabular}{|l|r|r|r|}
\hline \multicolumn{5}{|c|}{ Jam Kerja 09:00 - 10:00 Solution } \\
\hline $\mathrm{k}$ & $\begin{array}{l}\text { Prob (num } \\
\text { in sys = k) }\end{array}$ & $\begin{array}{l}\text { Prob (num in } \\
\text { sys }<\text { k) }\end{array}$ & $\begin{array}{l}\text { Prob (num } \\
\text { in sys }>\text { k) }\end{array}$ \\
\hline 0 &, 13 &, 13 &, 87 \\
\hline 1 &, 2 &, 32 &, 68 \\
\hline 2 &, 15 &, 48 &, 52 \\
\hline 3 &, 12 &, 59 &, 41 \\
\hline 4 &, 09 &, 68 &, 32 \\
\hline 5 &, 07 &, 76 &, 24 \\
\hline 6 &, 05 &, 81 &, 19 \\
\hline 7 &, 04 &, 85 &, 15 \\
\hline 8 &, 03 &, 89 &, 11 \\
\hline 9 &, 03 &, 91 &, 09 \\
\hline 10 &, 02 &, 93 &, 07 \\
\hline 11 &, 02 &, 95 &, 05 \\
\hline 12 &, 01 &, 96 &, 04 \\
\hline 13 &, 01 &, 97 &, 03 \\
\hline 14 &, 01 &, 98 &, 02 \\
\hline 15 &, 01 &, 98 &, 02 \\
\hline 16 &, 0 &, 99 &, 01 \\
\hline
\end{tabular}

\begin{tabular}{|c|c|c|c|}
\hline \\
\hline $\mathrm{k}$ & $\begin{array}{l}\text { Prob (num } \\
\text { in sys = k) }\end{array}$ & $\begin{array}{l}\text { Prob (num in } \\
\text { sys }<=k \text { ) }\end{array}$ & $\begin{array}{l}\text { Jam Kerja 09:00 - 10:00 Solution } \\
\begin{array}{|l|l|l}\text { Prob (num Prob (num in } & \text { Prob (num }\end{array}\end{array}$ \\
\hline 17 &, 0 & ,99 &, 01 \\
\hline 18 & 0 & 1 & 01 \\
\hline 19 & 0 & 1 &, 01 \\
\hline 20 & 0 & 1 & 01 \\
\hline 21 & 0 & 1 & 0 \\
\hline 22 & 0 & 1 &, 0 \\
\hline 23 & 0 & 1 & 0 \\
\hline 24 & 0 & 1 & 0 \\
\hline 25 & 0 & 1 & 0 \\
\hline 26 & 0 & 1 &, 0 \\
\hline 27 & 0 & 1 & 0 \\
\hline 28 & 0 & 1 & 0 \\
\hline 29 & 0 & 1 & 0 \\
\hline 30 & 0 & 1 & 0 \\
\hline
\end{tabular}

\section{Kesimpulan}

Berdasarkan simulasi diperoleh kesimpulan bahwa untuk mengoptimalkan serta mempertahankan pelayanan pada Bank X dilakukan penambahan teller pada jam kerja pukul 09:00-10:00 sehingga pengurangan waktu rata-rata yang dihabiskan seorang nasabah untuk 
menunggu dalam antrean yaitu dari sebanyak 4,51 menit setelah dilakukan penambahan teller menjadi 0,1 menit. Selain itu terjadi pula pengurangan nasabah yang mengantre dari 2 orang menjadi 0 orang. Model antrean yang tepat digunakan pada PT Bank X adalah Multi ChannelSingle Phase dan disiplin pelayanan First Come First Served (FCFS).

\section{DAFTAR PUSTAKA}

Andika, A.M.H dan Novriyenni. 2018. Simulasi dan Analis Antrean Pelayanan Bank Syariah Mandiri. Jurnal Sistem Informasi Kaputama (JSIK) 2(1):9-19. Diakses pada tangal 26 November 2020.

Ardi, Wayan. 2015. Penerapan Sistem Antrean pada PT. Bank Rakyat Indonesia (Persero) Tbk. Cabang Masamba. Skripsi tidak diterbitkan. Palopo: Program Sarjana Sains, Universitas Cokroaminoto Palopo.

Mayangsari, Yashinta., dan Estik H.P. 2016. Sistem Antrean Teller Bank Mandiri Sebagai Upaya Meningkatkan Efisiensi Kecepatan Transaksi. Jurnal Ekonomi \& Bisnis 1(1):4960. Diakses pada tanggal 26 November 2020.

Mehandiratta. 2011. Applications of Queuing Theory In Health Care. International Journal of Computing and Business Research. 2(2). Punjab: Chitkara University.

Pardede, A.M.H. 2013. Simulasi Antrean Pelayanan Berkelompok Oleh Banyak Server. Tesis tidak diterbitkan. Medan: Program Pasca Sarjana - UniversitasSumatera Utara.

Pardede, A.M.H., H. Hawengkang., dan Z. Situmorang. 2014. Simulasi Antrean Kedatangan Berkelompok dengan Pelayanan Weibull Oleh Banyak Server.Jurnal Teknol. Inf. dan Komun 3(1):1-10. Diakses pada tanggal 22 Februari 2020.

Simamora, R.J. 2010. Simulasi Antrean Multiple Server dengan Pola Kedatangan Berkelompok. Tesis tidak diterbitkan. Yogyakarta: Program Pasca Sarjana Ilmu Komputer, UniversitasGadjah Mada. 